\title{
ON VICE PRESIDENTS
}

\section{Some summer thoughts from the Society's President}

These are the dog days. This is the time of year we all expect to take some time off for ourselves; to relax, restore ourselves, and enjoy our families and friends. We all look forward to this. While the arrangement for a summertime hiatus from our professional responsibilities is sometimes difficult, it is complicated in the extreme for your Society's Vice Presidents, Woody White and Elton Kaufmann, whose activities on behalf of the MRS are approaching a frantic pace, while the rest of us enjoy the summer.

Rather than simply enumerate the duties and responsibilities of the Vice Presidents, I would prefer to use a bit of space in this Bulletin to describe for you some behind-the-scenes activities that this pair are leading.

For his part, Woody is coordinating the activities of a special committee

\section{Nominations Open}

\section{For Student Awards}

Each year the Materials Research Society recognizes exceptionally successful and promising students of materials science at the Annual Meeting. Additionally, the students are given travel assistance to attend the meeting, and deliver a paper before one of its symposia.

Faculty members who can recommend such student scientists should request an application from the Society's Secretariat. The address is Ernest Hawk, Executive Secretary, Materials Research Society, 110 Materials Research Laboratory, University Park, PA 16802.

Completed applications must be received no later than Sept. 15 by the Chairman of the Nominating Committee, Past President Clyde J.M. Northrup Jr., Sandia National Laboratory, Albuquerque, NM 87185. that has been charged with making recommendations to the Council regarding the best possible arrangement for the long-term disposition of our staff function. In this pursuit, Woody has organized communications between the five committee members and has proposed and documented a good number of the options being considered. $\mathrm{He}$ has unquestionably captured the record for highest personal consumption of MRS stationary, and his penchant for arranging conference calls is fast becoming legendary. All this in addition to the standard committee oversight and administrative functions he handles with seeming indefatigability. And, as you will see elsewhere in these pages, Woody has spent time on our behalf assisting European members of our Society in organizing.

No less active has been Elton Kaufmann, who has himself played a major role in the activities of the White Committee. Elton, like Woody, has recently returned from an organizing foray to Europe. On his journey, he visited several materials laboratories and acquainted the scientists there not only with our activities but also with the efforts of the European community to organize an MRS affiliate. He has also taken a longer view and begun in earnest planning for our Spring - 1985 meeting in San Francisco. The groundwork for this meeting has already been done, and the plan is an extraordinarily well crafted foundation for a successful meeting.

It is a very distinct pleasure to work with colleagues as capable and committed as Woody and Elton. They make my job a lot easier. They make the Society a lot stronger.

By the same token, Woody and Elton aren't the only scientists active in the leadership of the MRS who work hard and long for the group's benefit. For example, Gordon Pike is a co-chairman not only of the coming Boston meeting, but of the Albuquerque meeting in the

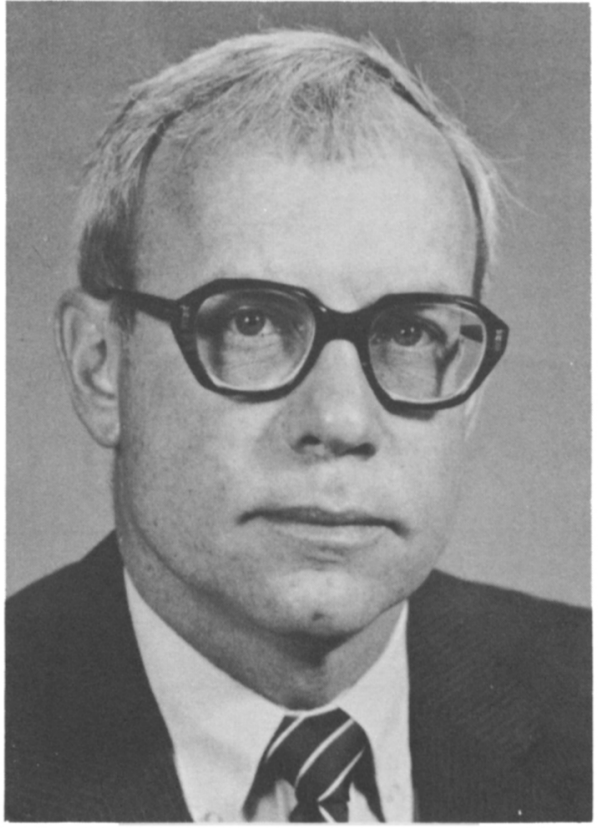

\section{HARRY LEAMY}

spring. Bill Appleton is another of the Boston co-chairmen. Gordon, Bill and Bernie Kear, the third co-chairman of the Annual Meeting, are by now well aware of the incredible responsibilities that meeting imposes. No summer break for them.

Clyde Northrup, the Past President, too has invested a good part of his summer in the MRS. As Chairman of the Nominating and Awards Committees, he has overseen the election being conducted in these pages, and the process by which the Society's Von Hippel Award will be given at Boston.

Familiar as I am with the workings of the MRS, and the heavy burdens it imposes on those who choose to participate actively in it, I am nonetheless astonished and impressed by the labors of the individuals I've mentioned here, and many others I won't mention for fear of omitting someone. Collaboration with people of this calibre is reward enough for a commitment of time and energy to the MRS.

Harry Leamy

President 